dation in 1928, the British Society for International Bibliography has worked to secure such collaboration. A National Committee of Representatives of Abstracting and Indexing Services has now been formed by the Society. 'This committee will investigate and solve the problems involved in indexing every useful article in the world's output of scientific and technical literature, and the associated services will work in free co-operation to produce a comprehensive index. In order that a standard system of indexing may be made available, the British Standards Institution has arranged to publish the fourth edition of Universal Decimal Classification as a British standard. In accordance with the practice of that Institution, each section of the classification will be produced in collaboration with institutions, societies and individuals specially interested, so that the classification will have the approval of expert opinion. The Library Association is represented on the Publication Committee and will give its valuable aid to this great work. Thus there is, at last, good hope that a comprehensive index to knowledge will be achieved and in the most efficient form.

\title{
THERMODYNAMICS AND CHEMISTRY
}

\section{(I) Thermodynamics and Chemistry}

By Prof. F. H. Macdougall. Third edition. Pp. ix +491. (New York: John Wiley and Sons, Inc. ; London: Chapman and Hall, Ltd., 1939.) $30 s$. net.

\section{(2) Thermodynamics}

For Chemical Engineers. By Prof. Harold C. Weber. Pp. vii +264. (New York: John Wiley and Sons, Inc.; London : Chapman and Hall, Ltd., 1939.) $19 s .6 d$. net.

(1)

ROF. F. H. MACDOUGALL'S book was recognized in its two previous editions as particularly suited to the needs of students of chemistry, and in the new edition, which has been extensively revised since the appearance of the second edition in 1926, this feature is again maintained.

Apart from minor but useful changes in various parts of the text, the main alterations comprise a much more detailed treatment of fugacity and activity and of the modern theory of strong electrolytes than was contained in previous editions. The last chapter contains a brief but clear account of the methods of calculating thermodynamic functions by statistical methods, and this should serve admirably as an introduction to the larger works on this subject. Examples are given at the ends of the chapters but unfortunately no answers are provided, which seriously diminishes their utility to both students and teachers. As in previous editions, an appreciable part of the book is concerned with phase rule diagrams, and although this provides a welcome break for the student by leading him through easy paths before taking him into the more difficult part of the book which follows, it is doubtful whether this matter is not better dealt with in a separate treatise.

The whole book is carefully written and the standard is high; many rather obscure points which are either not mentioned at all in other works or are not sufficiently explained are here clearly elucidated. As is to be expected, particular emphasis is laid on electrochemistry, since this has contributed so largely to modern research in the fields with which the book deals. Every advanced student of chemistry could read this book with profit.

(2) Prof. H. C. Weber's book strikes a new note in the literature of thermodynamics. The engineer has long made use of the thermodynamic functions but is probably not very familiar with the chemical applications of the subject, and although the chemist has very recently become aware of the immense utility of thermodynamics, he has usually very little knowledge of those parts of the subject which do not deal with systems in equilibrium of the type which he aims at setting up in the laboratory. Such subjects as the flow of fluid, refrigeration, the various types of power-cycles, and the thermodynamics of steam and internal combustion engines, are outside the scope of books devoted to the chemical aspects of thermodynamics. They are, however, vitally important to the chemical engineer.

The present book attempts to correlate these two branches of the subject. It deals with the engineering aspects in a way calculated to attract and inform the chemist, and with the chemical aspects in a form which the engineer would do well to assimilate. In the second field, there are chapters on fugacity and activity, equilibrium constants, partial molal quantities, electrochemistry, and the so-called third law. The book thus lays the foundations of a treatment of thermodynamics which is particularly suited to the chemical engineer. There are good numerical examples at the ends of the chapters but, as is so often the case with American books, no answers are provided.
J. R. Partington. 